Original Research Paper

\title{
Risk Factors of Renal Aspergillosis in Pigeons (Columba livia): Field Study
}

\author{
${ }^{1}$ Bagus Uda Palgunadi, ${ }^{2}$ Kurniasih and ${ }^{1}$ Yos Adi Prakoso \\ ${ }^{I}$ Faculty of Veterinary Medicine, University of Wijaya Kusuma Surabaya, East Java, Indonesia \\ ${ }^{2}$ Department of Pathology, Faculty of Veterinary Medicine, University of Gadjah Mada, Yogyakarta, Indonesia
}

\author{
Article history \\ Received: 24-03-2019 \\ Revised: 29-05-2019 \\ Accepted: 13-06-2019 \\ Corresponding Author: \\ Yos Adi Prakoso \\ Faculty of Veterinary \\ Medicine, University of Wijaya \\ Kusuma Surabaya, East Java, \\ Indonesia \\ Email: yos.vet.docter@gmail.com
}

\begin{abstract}
Aspergillosis is the common infectious diseases in the avian species. Aspergillosis causes granulomatous lesions in the lung and upper respiratory system and rarely reported regarding its infection in the kidney. This study aims to analyse the risk factors of renal aspergillosis in the pigeon (Columba livia) and its association to aflatoxicosis and CD4+/ CD8 + depression. Twenty-dead pigeons, feed and litter randomly collected from 10-local breeders. Each breeder was asked to fill out the questionnaire. Microbiology, immuno-histopathology and detection of aflatoxin were performed on the collected specimens. The data was analysed using SPSS 16. The results revealed that the prevalence of Aspergillus belonging to the "Fumigati section" was $85 \%$ and $80 \%$ in lungs and kidneys, respectively. Moreover, the hyphae and granulomatous inflammation with minimal expression of CD4+/CD8+ are observed from pigeons kidney. This study reflected that contamination of Aspergillus belonging to the "Fumigati section" in the litter and air significantly affect the occurrence of pigeon's renal aspergillosis.
\end{abstract}

Keywords: Aflatoxicosis, CD4+, CD8+, Pigeon, Renal Aspergillosis, Risk Factors

\section{Introduction}

For long decades, the development of the poultry industry faces a global disease problem. The poultry's diseases are caused by various infectious agents such as virus, bacteria, chlamydia, parasites and fungus. Several fungi that are highly pathogen to avian species are Aspergillus flavus, A. niger and A. fumigatus (Arne et al., 2011; Ghaemmaghami et al., 2016). The infection of Aspergillus species is known as aspergillosis and is firstly reported on avian by Urbain and Guillot in 1938 (Okoye and Okeke, 1986). Moreover, those Aspergillus species have high morbidity and mortality that impacts on the economic losses. The prevalence of aspergillosis increases synergist with a weather change especially in summer and, it occurs in both wild and domesticated birds (Alvarez-Perez et al., 2010).

High incidence of aspergillosis in summer is due to the dusty environment that facilitates the conidia of Aspergillus to transmit to the respiratory tract. In the respiratory system, the avians' body high temperature promotes the conidia to form hyphae and mycelia. Those infections cause overwhelmed inflammatory responses and generated granulomatous lesions (Tochigi et al., 2013). Further, the hyphae spreads to other organs such as liver, brain and kidney via the circulatory system (Beernaert et al., 2010). Unfortunately, kidney aspergillosis in avian species is unreported yet.

Aspergillus synthesis the aflatoxin to aggravates the infection in a suitable condition. Aflatoxin is the one of common mycotoxin that potential as the carcinogenic agent (Khoshpey et al., 2011). Chronic exposure can depress the systemic immune function, malnutrition, bile duct proliferation, hepatic lesion and tumorigenesis. Food contamination is the main port of entry of aflatoxin (Yu, 2012). Aflatoxin causes a disease called aflatoxicosis. As an Aspergillus synthesis product, aflatoxin is thought to be associated with the incidence of aspergillosis.

Even so, there are no reports regarding the synergistic effects of aflatoxicosis and aspergillosis or vice versa. Aflatoxicosis depress the immune system that is suspected supports the aspergillosis, or aspergillosis creates aflatoxicosis in several conditions. CD4+ and CD8+ are potential to destruct the conidia during the fungal infection. $\mathrm{CD} 4+$ is one of $\mathrm{T}$ cells type that regulates the tissues repair in human aspergillosis (Jolink et al., 2014). In the mice study, CD4+ extend the life span of infected mice with Aspergillus (Bozza et al., 2003). As T cell cytotoxic, CD8+ control the tissue from 
Aspergillus invasion (Tao et al., 2006). The role of CD4+/CD8+ in human have been reported, however not in poultry. As the unique case, the renal aspergillosis has a piece of limited information and report. Moreover, its risk factors and the function of $\mathrm{CD} 4+/ \mathrm{CD} 8+$ become essential to explore. Therefore, this study aims to analyse the occurrence of renal aspergillosis in pigeons, its risk factors and association with CD4+/CD8+ depletion.

\section{Materials and Methods}

\section{Sampling}

Total 20-dead pigeons (Columba livia) are carried from 10-local breeders in sub-district of Krembung, East Java, Indonesia from December 2018 until January 2019.

\section{Necropsy}

The necropsy was performed following the standard guideline demonstrated by previous study (Brownlie and Munro, 2016). Several organs were obtained such as brain, lung, liver, spleen, kidney, digestive tracts. Each specimen is separated into two part. The first organ portion was stored in the $10 \%$ Neutral Buffer Formalin (NBF) for histopathological examination. The second was kept in sterile plastic for microbiological test. Further, the litter and feed of pigeons were collected using aseptic procedure and it was transported to the Laboratory of Bacteriology, Faculty of Health, University of Muhammadiyah Sidoarjo.

\section{Microbiological Examination}

The Sabouraud Dextrose Agar (SDA) is used to isolate both fungi and yeast from the pigeons' organs. Further, the isolation and identification of airborne microbial from the pigeon's cage environment were performed by sedimentation technique with exposing the open Petri-dishes that contain culture media with room air condition for 2-h (Yagoub and Agbash, 2010; Shams-Ghahfarokhi et al., 2014).

\section{Questionnaire}

The breeder is interviewed and the data is used as supplementary materials. Several questions were recorded on the questionnaire to facilitate the breeders to answer during the interview. The points of observation were age, sex, history of the disease, types of feed, the knowledge of breeder on the pigeon's disease and aspergillosis.

\section{Histopathology and Immunohistochemistry}

After the fixation using $10 \% \mathrm{NBF}$, the organs were dehydrated using graded alcohol and were cleaned using xylene. Further, it is kept in liquid paraffin and blocked. The organ block was cut using microtome in $5 \mu \mathrm{m}$ of thickness. The tissue sections were placed on the water bath and mounted to the glass slides. This study utilised three types of staining procedures that are hematoxylin and eosin (H\&E), Periodic Acid - Schiff (PAS); and Immunohistochemistry (IHC) against antibody antiCD4+ and CD8+ (Alturkistani et al., 2016).

\section{Morphometry}

The morphometry is conducted by a single pathologist under a blindfold situation. The H\&E and IHC slides were scored using modified scoring system as follow: absence (0); minimal (1); mild (2); moderate (3); and severe (4). The PAS slide was scored by the appearance of hyphae, unfound (1) and found (2) (Gibson-Corley et al., 2013).

\section{Enzyme-linked Immunosorbent Assays (ELISA)}

The ELISA was performed to analyse the residue of aflatoxin on the feeds and the organ of pigeons. It was conducted following the previous procedure (Prakoso et al., 2018). Based on the previous study, the detection limit of this assay is $1.25 \mathrm{ng} \mathrm{g}^{-1}$ for the poultry feeds (Rossi et al., 2012).

\section{Data Analysis}

All the data were reported as the semi-quantitative data and determined using the bivariate and multivariate methods. Those data are used to elucidate the risk factors that influence renal aspergillosis in pigeons. The data were analysed using SPSS 16 with a probability value at level of $\mathrm{P}<0.05$.

\section{Results}

\section{Microbiological Examination}

The microbiological test performed from several specimens, were isolated and identified as the Aspergillus belonging to the "Fumigati section". The prevalence of Aspergillus belonging to the "Fumigati section" was $85 \%$ from lung (17/20) and $80 \%$ from kidney $(16 / 20)$ of pigeons. However, there is no growth of fungus from the brain, liver, spleen and digestive tract. Surprisingly, the Aspergillus belonging to the "Fumigati section" was isolated and identified from litter, pigeon's feed and air from pigeon's cage environment as follow $80 \%(16 / 20)$, $90 \%(18 / 20)$ and $85 \%(17 / 20)$.

\section{Risk Factors}

The statistical result showed that the renal aspergillosis is affected by several risk factors such as the contamination of Aspergillus belonging to the "Fumigati section" in the cage litter and air in pigeon's cage environment. Those factors showed a significant value $(\mathrm{P}<0.05)$. On the other hands, the Aspergillus belonging to the "Fumigati section" contamination in pigeon's feed, the occurrence of aflatoxicosis and lungs 
aspergillosis have no effects and association on the pigeon's renal aspergillosis (Table 1).

Type of feeds, owner's knowledge of the pigeon's disease and aspergillosis and the aflatoxin contamination in feeds are categorised as the other risk factors. However, those factors did not influence the occurrence of renal aspergillosis. The contamination of aflatoxin in feeds partially increases the renal aspergillosis in pigeons with the highest odds ratio 2.105 times even though it has no significant differences (Table 2). More large samples may be needed to explore these effects.

\section{Histopathology}

The histopathological change is observed from the collected specimens. It showed the diverse changing from necrosis, inflammation, the appearance of hyphae section, bile duct proliferation and lymphoid tissue depletion. The histopathological assessment was expressed as the means score from the total of 20-dead pigeons. Inflammation and necrosis were observed from lung and kidney with the highest score, followed by the bile duct proliferation of liver and white pulp depletion of the spleen (Fig. 1).

The aspergillosis pathognomonic lesions were granulomatous inflammation and giant macrophages, necrotising tissue and the appearance of hyphae section inside or surrounding a zone of demarcation. Those histopathological change were found in the lung $(11 / 20)$ (Fig. 2B) and massively in the kidney (17/20) (Fig. 2D and $2 \mathrm{E}$ ). The liver showed bile duct proliferation with inflammation that is a typical lesion for aflatoxicosis $(12 / 20)$ (Fig. 2G). The different result is attested by the microscopical appearance of the brain, spleen and digestive tract that indicates the healthy tissue structure.

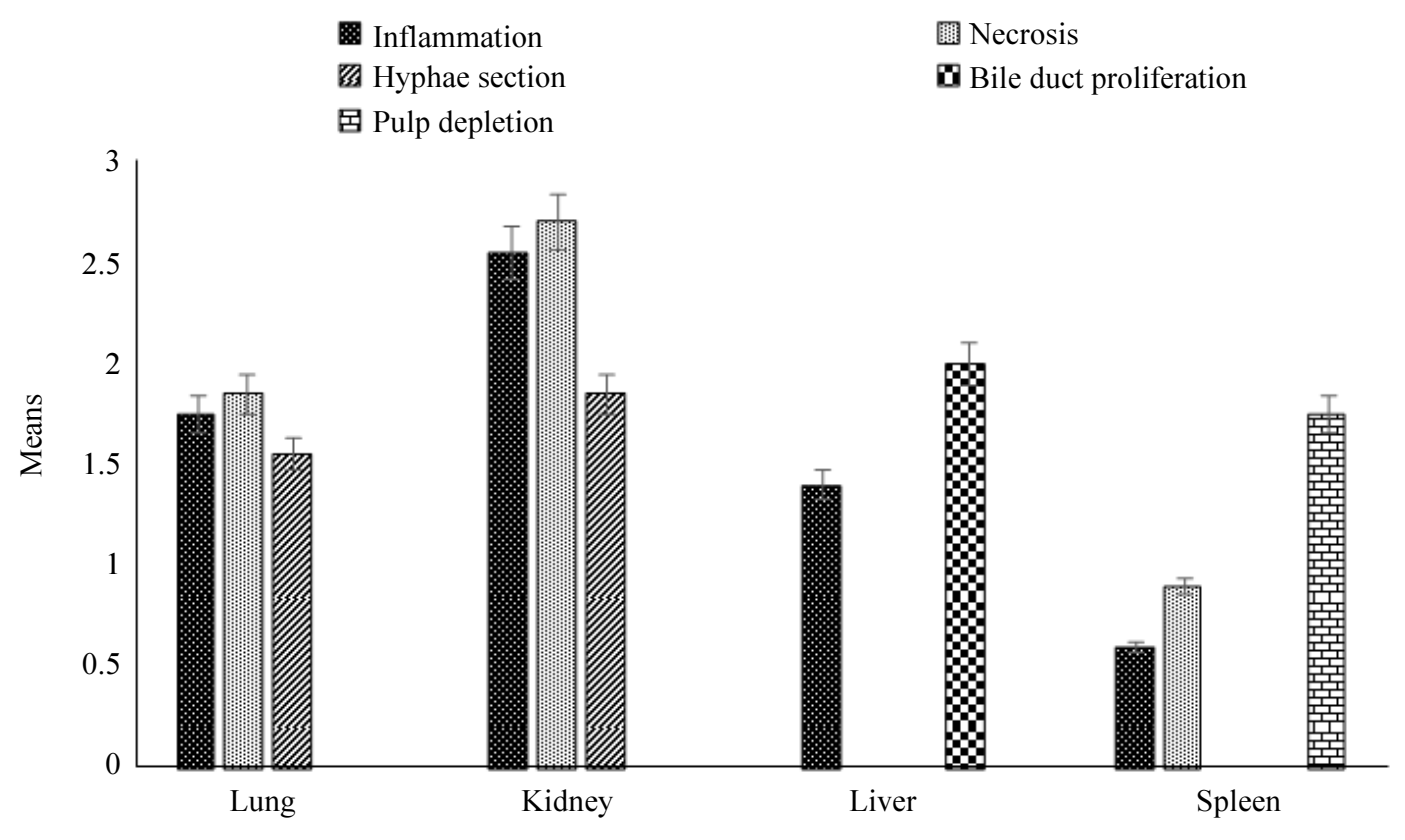

Fig. 1: Means of the histopathological score from the pigeon's organs

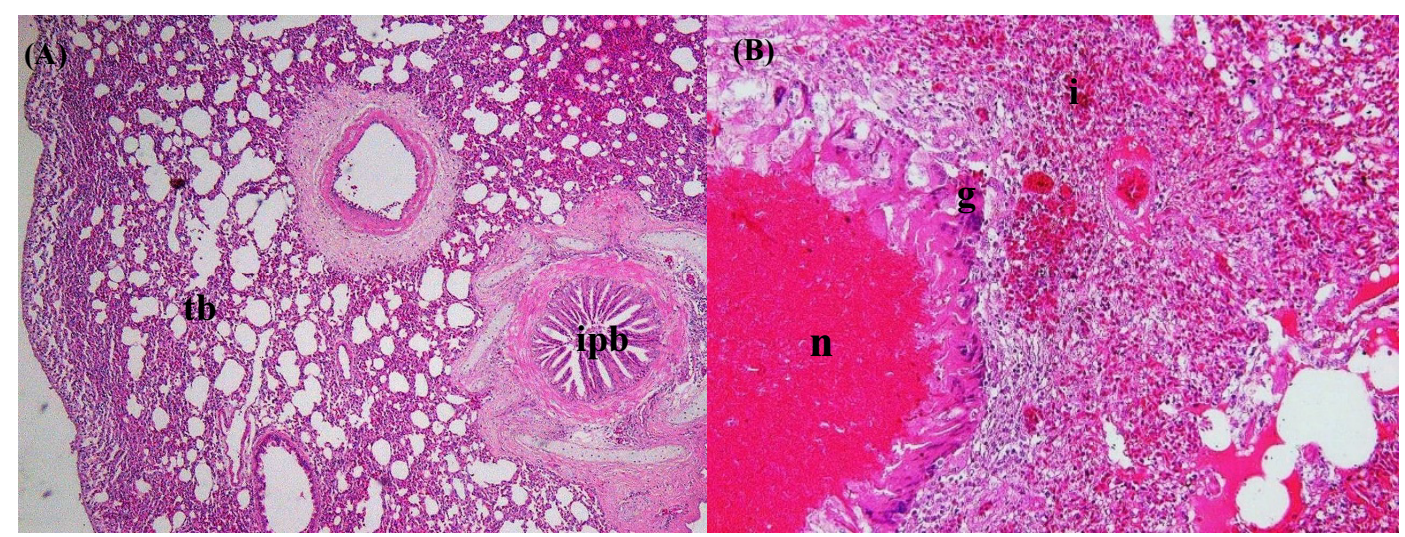




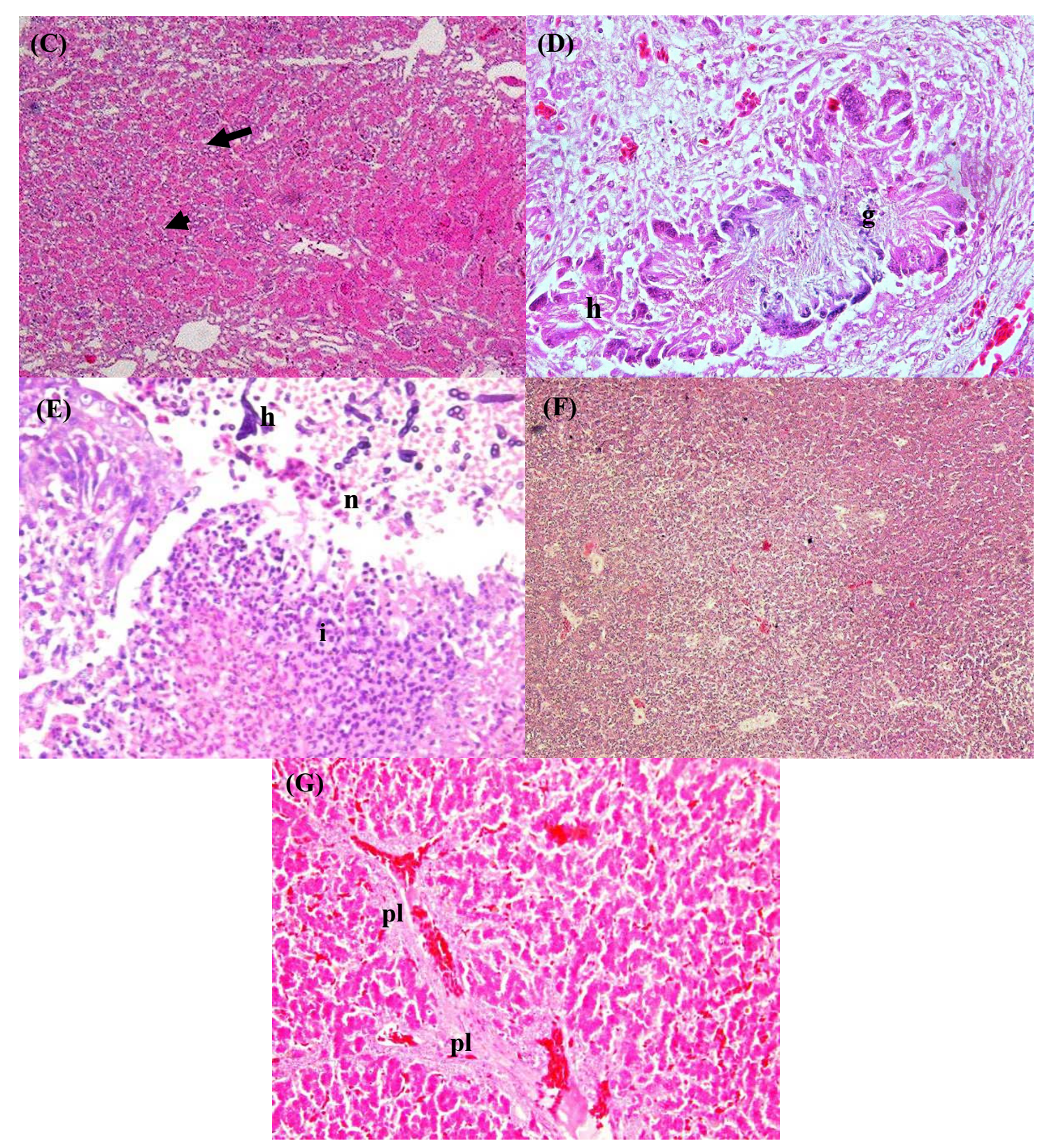

Fig. 2: Histopathological change of lung, kidney and liver from pigeons infected by Aspergillus belonging to the "Fumigati section". Normal appearance of lung in uninfected pigeon that consist of intrapulmonary primary bronchi (ipb) and intact tertiary bronchi (tb) without inflammation (A); granulomatous necrosis (n) was surrounded by giant macrophages (g) and inflammatory cells predominantly heterophil and eosinophil (i) in the lung (B); normal section of kidney with glomerulus (arrow) and tubules (arrowhead) (C); the hyphae (h) were covered by giant macrophages (g) and inflammatory cells (i) in the centre of necrosis $(n)$ of kidney from infected pigeons ( $\mathrm{D}$ and $\mathrm{E}$ ); dense hepatocytes in a normal liver $(\mathrm{F})$; and the bile duct proliferation (pl) of liver indicates the aflatoxicosis in an infected pigeon (G). H\&E, 40×(A, B, C, F); 100× (D, G); PAS, 100×(E)

\section{Immunohistochemistry}

Renal aspergillosis has a significant impact on the immune-expression of $\mathrm{CD} 4+$ in kidney and spleen $(\mathrm{P}<0.05)$. Further, the minimal immune-expression of CD8+ were observed in the kidney $(\mathrm{P}<0.05)$. This result proved that minimal expression of $\mathrm{CD} 4+$ and
CD8+ in a kidney increase risk of pigeon renal aspergillosis. Low expression of CD4+ in the spleen was maybe caused by aflatoxicosis. There is no significant difference on the others $(\mathrm{P}>0.05)$. This result showed that the decrease of $\mathrm{CD} 4+, \mathrm{CD} 8+$ and CD4+/CD8+ on lungs and liver were unrelated to pigeon renal aspergillosis (Table 3 ). 
$\underline{\text { Table 1: Association between variable and renal aspergillosis in pigeons }}$

\begin{tabular}{|c|c|c|c|c|c|}
\hline \multirow[b]{2}{*}{ Variable } & \multirow[b]{2}{*}{ Information } & \multicolumn{2}{|c|}{ Aspergillosis } & \multirow[b]{2}{*}{$X^{2}$} & \multirow[b]{2}{*}{ P-value } \\
\hline & & $(+)$ & $(-)$ & & \\
\hline \multirow{7}{*}{$\begin{array}{l}\text { Aspergillus belonging to the "Fumigati } \\
\text { section" contamination in litter } \\
\text { Aspergillus belonging to the "Fumigati } \\
\text { section" contamination in feed } \\
\text { Aspergillus belonging to the "Fumigati } \\
\text { section" contamination in air } \\
\text { Aflatoxicosis }\end{array}$} & Positive & 16 & 0 & \multirow[t]{2}{*}{14.11} & \multirow[t]{2}{*}{$0.00 *$} \\
\hline & Negative & 1 & 3 & & \\
\hline & Positive & 16 & 2 & \multirow[t]{2}{*}{2.13} & \multirow[t]{2}{*}{0.14} \\
\hline & Negative & 1 & 1 & & \\
\hline & Positive & 16 & 1 & \multirow[t]{2}{*}{7.38} & \multirow[t]{2}{*}{$0.00 *$} \\
\hline & Negative & 1 & 2 & & \\
\hline & Yes & 8 & 3 & \multirow[t]{2}{*}{2.88} & \multirow[t]{2}{*}{0.08} \\
\hline & No & 9 & 0 & & \\
\hline \multirow{2}{*}{ Lungs aspergillosis } & Yes & 10 & 1 & \multirow[t]{2}{*}{0.86} & \multirow[t]{2}{*}{0.35} \\
\hline & No & 9 & 0 & & \\
\hline
\end{tabular}

*P-value $<0.05$ showed the significant different.

Table 2: Risk factors of renal aspergillosis in pigeons

\begin{tabular}{llllll}
\hline Variable & Coef. & SE & Coef./SE & OR & P-value \\
\hline Type of feeds & -2.75 & 2.25 & -1.22 & 0.06 & 0.22 \\
Knowledge of disease & -3.42 & 2.68 & -1.27 & 0.03 & 0.20 \\
Knowledge of aspergillosis & -3.97 & 3.35 & -1.18 & 0.01 & 0.23 \\
Residue of aflatoxin in feeds & 0.74 & 1.22 & 0.60 & 2.10 & 0.54 \\
\hline
\end{tabular}

Coef. = Coefficient; $\mathrm{SE}=$ Standard Error; OR $=$ Odds Ratio; $*$ P-value $<0.05$ showed the significant different

Table 3: Comparison between score of CD4+, CD8+ and CD4+/CD8+ from the pigeons with and without renal aspergillosis

\begin{tabular}{|c|c|c|c|c|}
\hline \multirow[b]{2}{*}{ Organ } & \multirow[b]{2}{*}{ IHC Parameter } & \multicolumn{2}{|c|}{ Renal Aspergillosis } & \multirow[b]{2}{*}{ P-value } \\
\hline & & With & Without & \\
\hline \multirow[t]{3}{*}{ Lungs } & CD4+ & $1.58 \pm 0.71$ & $2.33 \pm 0.57$ & 0.10 \\
\hline & CD8+ & $1.70 \pm 0.46$ & $1.66 \pm 0.57$ & 0.89 \\
\hline & CD4+/ CD8+ & $1.05 \pm 0.63$ & $1.50 \pm 0.50$ & 0.27 \\
\hline \multirow[t]{3}{*}{ Kidney } & $\mathrm{CD} 4+$ & $1.23 \pm 0.43$ & $3.33 \pm 1.15$ & $0.00 *$ \\
\hline & CD8+ & $1.52 \pm 0.51$ & $3.00 \pm 0.00$ & $0.00 *$ \\
\hline & CD4+/ CD8+ & $0.88 \pm 0.37$ & $1.11 \pm 0.38$ & 0.34 \\
\hline \multirow[t]{3}{*}{ Liver } & CD4+ & $1.11 \pm 0.78$ & $0.66 \pm 0.57$ & 0.35 \\
\hline & $\mathrm{CD} 8+$ & $1.64 \pm 0.60$ & $1.00 \pm 0.00$ & 0.08 \\
\hline & CD4+/ CD8+ & $0.70 \pm 0.53$ & $0.66 \pm 0.57$ & 0.90 \\
\hline \multirow[t]{3}{*}{ Spleen } & $\mathrm{CD} 4+$ & $2.17 \pm 0.63$ & $4.00 \pm 0.00$ & $0.00 *$ \\
\hline & $\mathrm{CD} 8+$ & $2.35 \pm 0.70$ & $3.00 \pm 0.00$ & 0.13 \\
\hline & CD4+/ CD8+ & $1.02 \pm 0.56$ & $1.33 \pm 0.00$ & 0.37 \\
\hline
\end{tabular}

*P-value $<0.05$ showed the significant different

\section{Discussion}

A. fumigatus is the one fungal species that causes infection in vertebrates. The prevalence of aspergillosis in human reaches a million people and it has become a global problem (Bongomin et al., 2017). Several cases of $A$. fumigatus infection have reported in canine (Magro et al., 2017), cattle, horse, cat and nonhuman primates (Seyedmousavi et al., 2015), bottlenose dolphin (Cassle et al., 2016) and among the avian species (Cafarchia et al., 2014). This study elucidated that contamination of Aspergillus belonging to the "Fumigati section" in the litter and air influence to the incidence of aspergillosis. The previous study demonstrates the invasive of aspergillosis can spreads through the water, air and household appliances
(Paulussen et al., 2017). Those abilities are due to its resistance against the extreme condition. Aspergillus can also utilise a wide variety of substrate to resist in the environment (Cray et al., 2013).

Dust and wind are the most frequently reported as the mediators of the conidia spreading in the environment. A. fumigatus infection promotes the pneumonic aspergillosis because of its route of infection via the respiratory system, commonly. Conidia are inhaled by the host and leading to infection. In the lung, the conidia accumulate and forms the biofilm in bronchiole, alveoli (Boisvert et al., 2016) and air sacs (Souza and Degernes, 2005). Those conidia can be eliminated by the mucociliary epithelial and other immune defence system on the lung tissue in a healthy organism. On the other hands, the conidia survive and promote lung infection 
when dysfunction of the immune system has occurred.

The dysfunction of the immune system that promotes by aspergillosis are neutropenia or heteropenia (Garth and Steele, 2017). Glucocorticoid therapy is known as another factor that impairs the immune system and increases the risk of aspergillosis (Lewis and Kontoyiannis, 2009). The dysfunction of the immune response gives a chance for the conidia to germinate and become mycelia. The mycelia invade the macrophages, lungs epithelial and vascular endothelial. Those mechanisms are defined as Invasive Aspergillosis (IA) (Barton, 2013). Extensive colonisation of Aspergillus in lung tissue causes severe necrosis, attracts the heterophil to forms the zone of demarcation around the necrotising area and attracts the macrophages to enfold the mycelia by forming the giant macrophages. The severe inflammation increases lung vascularisation and its compensation is generating port of entry of conidia to spreads systemically. This mechanism then leads to systemic infection.

A. fumigatus systemic infection affects several organs with high blood circulation such as liver, brain, heart and kidney. Liver aspergillosis has a similar lesion to pulmonary aspergillosis (Zhang et al., 2018). Another study reported that pulmonary aspergillosis in immunocompetent patient affects the abdominal organ that causes hepatomegaly, splenomegaly and giant cells granuloma in the lymph node (Urgene et al., 2013). In the brain, aspergillosis causes cerebral infarct with neuropathological symptoms. Commonly, cerebral aspergillosis shows a low survival rate (Li et al., 2015). All the systemic aspergillosis lesion is due to invasive pulmonary aspergillosis and or in other words the lung is the main port of entry for aspergillosis.

Unfortunately, none of the previous studies has reported regarding renal aspergillosis in poultry. In this study, the renal aspergillosis creates a depression of the renal tubule with the severe necrotising area and is surrounded by giant macrophages. Further, the pathognomonic lesion in the histopathology was the presence of sunflower-like fungi nodes in the kidney (Li et al., 2015). The hyphae are also presented. The immunocompetent is exhibited in the infected pigeons. The immunocompetent profile of the infected pigeons is determined by the immunohistochemistry of CD4+/CD8+ in several organs. The depression of CD4+/CD8+ impairs the avian immune system during infection, such as aspergillosis (Chu et al., 2017). Those T-lymphocytes are significant to stimulate interferon- $\gamma$ in the serum that effective against several types of infections (Rohollahzadeh et al., 2018). This is similar to the previous study that demonstrated Aspergillus infection in immunocompromised pigeons which seems to be contra-indicated and, it can generate both chronic and acute infection depends on the route of transmission (Beernaert et al., 2008). In this study, the depletion of
$\mathrm{CD} 4+/ \mathrm{CD} 8+$ are suspected due to feed's aflatoxin contamination even though, there is no significant difference regarding this parameter.

Further, the other tested risk factors such as contamination of Aspergillus belonging to the Fumigati in feeds, aflatoxicosis, type of feeds and owner's knowledge have not showed significant difference in this study. These have been described that the main port of entry of invasive aspergillosis and especially renal aspergillosis are from the respiratory system. The minimal information and understanding of the public society regarding renal aspergillosis in the pigeons provide the opportunities of Aspergillus infection to be transmit to human/zoonotic, potentially. The eradication of the infected pigeons is necessary to prevent transmission to the healthy pigeons. Moreover, the disinfection of pigeon-related items must be conducted by the owner because the location of pigeon's cage is close to the settlements commonly.

\section{Conclusion}

Pigeon's renal aspergillosis is an uncommon reported case in the poultry. The mechanism of infection of this disease is unclearly demonstrated by the previous studies. Contamination of Aspergillus belonging to the "Fumigati section" in the air and litter was the main risk factors of renal aspergillosis. Histopathological change of the renal aspergillosis is similar to the other invasive lesions. However, the depletion of $\mathrm{CD} 4+/ \mathrm{CD} 8+$ is not contributing to the severity of renal aspergillosis histopathologically. The utilisation of a larger sample is necessary to prove and analyse the potential risk factors on the pigeon's renal aspergillosis.

\section{Acknowledgements}

All laboratory staffs from Faculty of Health, University of Muhammadiyah Sidoarjo were acknowledged for their assistant.

\section{Author's Contributions}

Bagus Uda Palgunadi, Kurniasih and Yos Adi Prakoso: Contribute equally to this study. All the authors approved the final manuscript.

\section{References}

Alturkistani, H.A., F.M. Tashkandi and Z.M. Mohammedsaleh, 2016. Histological stains: A literature review and case study. Global J. Health Sci., 8: 72-79. DOI: 10.5539/gjhs.v8n3p72

Alvarez-Perez, S., A. Mateos, L. Dominguez, E. Martinez-Nevado and J.L. Blanco et al., 2010. Polyclonal Aspergillus fumigatus infection in captive penguins. Vet. Microbiol., 144: 444-449. DOI: $10.1016 /$ j.vetmic.2010.02.026 
Arne, P., S. Thierry, D. Wang, M. Deville and G.L. Loc'h et al., 2011. Aspergillus fumigatus in poultry. Int. J. Microbiol., 2011: 746356-746356. DOI: $10.1155 / 2011 / 746356$

Barton, R.C., 2013. Laboratory diagnosis of invasive aspergillosis: From diagnosis to prediction of outcome. Scientifica, 2013: 459405-459405. DOI: $10.1155 / 2013 / 459405$

Beernaert, L.A., F. Pasmans, F. Haesebrouck and A. Martel, 2008. Modelling Aspergillus fumigatus infections in racing pigeons (Columba livia domestica). Avian Pathol., 37: 545-549. DOI: $10.1080 / 03079450802382280$

Beernaert, L.A., F. Pasmans, L. Van Waeyenberghe, F. Haesebrouck and A. Martel, 2010. Aspergillus infection in birds: A review. Avian Pathol., 39: 325-331. DOI: 10.1080/03079457.2010.506210

Boisvert, A.A., M.P. Cheng, D.C. Sheppard and D. Nguyen, 2016. Microbial biofilms in pulmonary critical care diseases. Ann. Am. Thoracic Soc., 13: 1615-1623. DOI: 10.1513/AnnalsATS.201603-194FR

Bongomin, F., S. Gago, R.O. Oladele and D.W. Denning, 2017. Global and multi-national prevalence of fungal diseases-estimate precision. J. Fungi (Basel, Switzerland), 3: 57-57. DOI: 10.3390/jof3040057

Bozza, S., K. Perruccio, C. Montagnoli, R. Gaziano and S. Bellocchio et al., 2003. A dendritic cell vaccine against invasive aspergillosis in allogeneic hematopoietic transplantation. Blood, 102: 38073814. DOI: 10.1182 /blood-2003-03-0748

Brownlie, H.W. and R. Munro, 2016. The veterinary forensic necropsy: A review of procedures and protocols. Vet. Pathol., 53: 919-928. DOI: $10.1177 / 0300985816655851$

Cafarchia, C., A. Camarda, R. Iatta, P. Danesi and P. Favuzzi et al., 2014. Environmental contamination by Aspergillus spp. in laying hen farms and associated health risks for farm workers. J. Medical Microbiol., 63: 464-470. DOI: 10.1099/jmm.0.065946-0

Cassle, S.E., N. Landrau-Geovannetti, L.L. Farina, A. Leone et al., 2016. Coinfection by Cetacean morbillivirus and Aspergillus fumigatus in a juvenile bottlenose dolphin (Tursiops truncatus) in the Gulf of Mexico. J. Vet. Diagn. Invest., 28: 729-734. DOI: $10.1177 / 1040638716664761$

Chu, J., Q. Zhang, Z. Zou, S. El-Ashram and Y. Guo et al., 2017. Co-infection of Chlamydia psittaci with H9N2, ORT and Aspergillus fumigatus contributes to severe pneumonia and high mortality in SPF chickens. Sci. Report, 7: 13997. DOI: $10.1038 / \mathrm{s} 41598-017-14519-1$

Cray, J.A., A.N. Bella, P. Bhaganna, A.Y. Mswaka and D.J. Timson et al., 2013. The biology of habitat dominance; Can microbes behave as weeds? Microbial Biotechnol., 6: 453-492. DOI: $10.1111 / 1751-7915.12027$
Garth, J.M. and C. Steele, 2017. Innate lung defense during invasive aspergillosis: New mechanism. J. Innate Immunity, 9: 271-280. DOI: 10.1159/000455125

Ghaemmaghami, S.S., M. Modirsaenii, A.R. Khosravi and M. Razzaghi-Abyaneh, 2016. Study on mycoflora of poultry feed ingredients and finished feed in Iran. Iranian J. Microbiol., 8: 47-54. PMID: 27092224

Gibson-Corley, K.N., A.K. Olivier and D.K. Meyerholz, 2013. Principle for valid histopathologic scoring in research. Vet. Pathol., 50: 1-22. DOI: $10.1177 / 0300985813485099$

Jolink, H., R.S. Hagedoorn, E.L. Lagendijk, J.W. Drijfhout and J.T. Van Dissel et al., 2014. Induction of $A$. fumigatus-specific CD4-positive T cells in patients recovering from invasive aspergillosis. Haematologica, 99: 1255-1263. DOI: 10.3324/haematol.2013.098830

Khoshpey, B., D.D. Frhud and F. Zaini, 2011. Aflatoxins in Iran: Nature, hazard and carcinogenicity. Iranian J. Public Health, 40: 1-30. PMID: 23113099

Lewis, R.E. and D.P. Kontoyiannis, 2009. Invasive aspergillosis in glucocorticoid-treated patients. Medical Mycol., 47: 271-281. DOI: $10.1080 / 13693780802227159$

Li, H., R. Zhu, R. She, C. Zhang and R. Shi et al., 2015. Case report associated with aspergillosis and hepatitis E virus coinfection in Himalayan griffons. Bio. Med. Res. Int., 2015: 287315-287315. DOI: $10.1155 / 2015 / 287315$

Li, W., N. Shafi, R. Periakaruppan, T. Valyi-Nagy and J. Groth et al., 2015. Cerebral aspergillosis in a diabetic patient leading to cerebral artery occlusion and ischemic stroke: A case report and literature review. J. Stroke Cerebrovascular Dis., 24: e39-e43. DOI: 10.1016/j.jstrokecerebrovasdis.2014.08.025

Magro, M., J. Sykes, P. Vishkautsan and B. MartinezLopez, 2017. Spatial patterns and impacts of environmental and climatic factors on canine sinonasal aspergillosis in Northern California. Frontiers Vet. Sci., 4: 104-104. DOI: $10.3389 /$ fvets. 2017.00104

Okoye, J.O.A. and C.N. Okeke, 1986. Pathogenecity of an isolate of Apergillus flavus in chickens. Avian Pathol., 15: 259-270. DOI: 10.1080/03079458608436286

Paulussen, C., J.E. Hallsworth, S. Alvarez-Perez, W.C. Nierman and P.G. Hamill et al., 2017. Ecology of aspergillosis: Insight into the pathogenic potency of Aspergillus fumigatus and some other Aspergillus species. Microbial Biotechnol., 10: 296-322.

DOI: $10.1111 / 1751-7915.12367$

Prakoso, Y.A., P. Rini, C.S. Aliviameita, A. Salasia and S.I.O. Kurniasih et al., 2018. The role of Sauropus androgynus (L.) Merr leaf powder in the broiler chickens fed a diet naturally contaminated with aflatoxin. J. Toxicol., 2018: 2069073-2069073. DOI: $10.1155 / 2018 / 2069073$ 
Rohollahzadeh, H., H. NNili, K. Asasi, S. Mokhayeri and A.H.A. Najjari, 2018. Respiratory and GI tract immune responses of broiler chickens following experimental infection with Newcastle disease's virus. Comparative Clin. Pathol., 27: 1241-1255. DOI: $10.1007 / \mathrm{s} 00580-018-2728-\mathrm{z}$

Rossi, C.N., C.R. Takabayashi, M.A. Ono, G.H. Saito and E.N. Itano et al., 2012. Immunoassay based on monoclonal antibody for aflatoxin detection in poultry feed. Food Chem., 132: 2211-2216. DOI: 10.1016/j.foodchem.2011.12.067

Seyedmousavi, S., J. Guillot, P. Arne, G.S. De Hoog and J.W. Mouton et al., 2015. Aspergillus and aspergilloses in wild and domestic animals: A global health concern with parallels to human disease. Med. Mycol., 53: 765-797. DOI: 10.1093/mmy/myv067

Shams-Ghahfarokhi, M., S. Aghaei-Gharehbolagh, N. Aslani and M. Razzaghi-Abyaneh, 2014. Investigation on distribution of airborne fungi in outdoor environment in Tehran, Iran. J. Environ. Health Sci. Eng., 12: 1-7. DOI: 10.1186/2052-336X-12-54

Souza, M.J. and L.A. Degernes, 2005. Mortality due to aspergillosis in wild swans in Northwest Washington State, 2000-2002. J. Avian Med. Surgery, 19: 98-106. DOI: jstor.org/stable/27823416

Tao, J., B.H. Segal, C. Eppolito, Q. Li and C.G. Dennis et al., 2006. Aspergillus fumigatus extract differentially regulates antigen-specific $\mathrm{CD} 4+$ and $\mathrm{CD} 8+\mathrm{T}$ cell responses to promote host immunity. J. Leukocyte Biol., 80: 529-537. DOI: 10.1189/jlb.0106026
Tochigi, N., O.Y. Ando, T. Wakayama, M. Shinozaki and M. Gocho et al., 2013. Histopathological implications of Aspergillus infection in lung. Mediators Inflammat., 2013: 809798-809798. DOI: $10.1155 / 2013 / 809798$

Urgene, U., Z. Akcali, D. Ozbalci, N. Nese and S. Senol, 2013. Disseminated aspergillosis due to Aspergillus niger in immunocompetent patient: A case report. Case Report Infect. Dis., 2013: 385190. DOI: $10.1155 / 2013 / 385190$

Yagoub, S.O. and E. Agbash, 2010. Isolation of potential pathogenic bacteria from the air of hospital-delivery and nursing rooms. J. Applied Sci., 10: 1011-1014. DOI: $10.3923 /$ jas.2010.1011.1014

$\mathrm{Yu}, \quad$ J., 2012. Current understanding on aflatoxin biosynthesis and future perspective in reducing aflatoxin contamination. Toxins (Basel), 4: 1024-1057. DOI: 10.3390\%2Ftoxins4111024

Zhang, X., M. Yang, J. Hu, H. Zhao and L. Li, 2018. Epidemiology of invasive pulmonary aspergillosis in patients with liver failure: clinical presentation, risk factors and outcomes. J. Int. Med. Res., 46: 819-827. DOI: 10.1177/0300060517729907 